\section{Cervical cancer: summary of the NIH consensus ${ }^{1}$}

1 This consensus statement summary was prepared and distributed for publication by the U.S. National Institutes of Health (NIH). Free single copies of the complete NIH consensus statement on cervical cancer may be ordered by mail from the NIH Consensus Program Information Center, P.O. Box 2577, Kensington, MD 20891, or by telephone (toll free) from 1-888-NIH-CONSENSUS. It is also available on the Internet at the web site http://consensus.nih.gov.
Carcinoma of the cervix is one of the most common malignancies in women, accounting for 15700 new cases and 4900 deaths each year in the United States of America. Worldwide, cervical cancer is second only to breast cancer as the most common malignancy in terms of both incidence and mortality. During the last 50 years in the United States, screening programs based on the Papanicolaou (Pap) smear and pelvic examination have led to a steep decline in incidence and deaths from cervical cancer.

Both invasive cervical cancers and precursor lesions have been firmly associated with the presence of human papillomavirus (HPV). It has also been well established that most squamous cell cancers of the cervix progress through a series of welldefined preinvasive lesions, and that during this usually lengthy process the disease can be easily detected by Pap smear screening. During the preinvasive stage, cervical squamous intraepithelial lesions (SIL) can be controlled with nearly uniform success and with the retention of fertility.

Many treatment and quality of life issues remain unresolved for women with cervical cancer. To address these issues, the National Cancer Institute and the U.S. National Institutes of Health (NIH) Office of Medical Applications of Research convened a Consensus Development Conference on Cervical Cancer on 1-3 April 1996. A 13-member panel, representing gynecologic, medical, and radiation oncologists, gynecologists, pathologists, epidemiologists, and patients, listened to presentations by experts and reached conclusions on four critical questions. These questions and answers are outlined below.

\section{How can efforts to prevent cervical cancer be strengthened?}

Despite the recognized benefits of Pap smear screening, substantial subgroups of U.S. women have not been screened or are not screened regularly. One-half of the women with newly diagnosed invasive cervical carcinoma have never had a Pap smear, and another $10 \%$ have not had a smear in the past five years. Unscreened populations include older women, the uninsured, ethnic minorities (especially Hispanics and elderly blacks), and poor women, particularly those in rural areas. To improve outreach, community-based, culturally sensi- 
tive approaches to reaching diverse ethnic populations are recommended.

Pap smear methods have changed little since the test was introduced in the late 1940s. Liquidbased specimen collection methods are currently being evaluated to improve sampling and cell preservation and presentation. In autumn 1995, the U.S. Food and Drug Administration (FDA) approved two automated instruments for rescreening smears evaluated as negative on the initial screen. Data from clinical trials suggest that these devices could reduce the rate of false negative smears, but neither their efficacy in routine practice nor their cost-benefit has been determined.

A strong causal relationship between HPV and cervical cancer and its precursors has been established. The virus is transmitted through sexual intercourse, with a peak prevalence of infection in women in the 22-25 age group. Primary prevention of HPV infections will require (1) directing education efforts toward adolescents and health care providers regarding the strong causal link between acquisition of HPV as a sexually transmitted disease and development of cervical cancer and its precursors, (2) encouraging delayed onset of sexual intercourse, (3) developing an effective prophylactic vaccine, and (4) developing effective vaginal microbicides. The data on the use of barrier methods of contraception to prevent the spread of HPV are controversial but do not support their effectiveness as a method of prevention.

Secondary prevention efforts must focus on (1) developing effective antiviral agents to treat HPV and/or prevent transformation, (2) developing therapeutic vaccines to prevent HPV progression, (3) improving the sensitivity and specificity of screening for the precursors of cervical cancer, and (4) expanding education and screening programs to target underscreened populations.

\section{What is the appropriate management of low-stage cervical cancer (stages I-IIA of the International Federation of Gynecology and Obstetrics [FIGO] classification)?}

The diagnosis of stage IA1 cervical squamous cell carcinoma should be based on cone biopsy, not punch cervical biopsy, preferably by using a technique that does not result in cauterized margins. At this stage, simple hysterectomy or cone biopsy (with negative margins) is virtually $100 \%$ curative; the choice of treatment should be influenced by the patient's desire to preserve fertility. At the present state of knowledge, a category of cervical adenocarcinoma that could be treated conservatively in order to preserve fertility cannot be identified.
Patients with IA2 lesions can be treated with primary radical or modified radical hysterectomy or primary radiation therapy with equivalent results. The choice of therapy should be influenced by such factors as ovarian preservation, comorbid conditions, and potential late side effects.

Patients with stages IB and IIA cervical cancer are appropriately treated with either radical hysterectomy with pelvic lymphadenectomy or radiation therapy (external beam therapy and brachytherapy) with equivalent results. The choice of therapy should be influenced by the same factors described in patients with stage IA2 disease. To minimize morbidity, primary therapy should avoid the routine use of both radical surgery and radiation therapy.

The optimal role for imaging studies in defining the extent of disease and in planning radiation therapy needs further investigation, as does the measurement of serum tumor markers in patients with invasive cervical cancer.

\section{What is the appropriate management of advanced-stage and recurrent cervical cancer?}

For stage IIB or greater, the standard of care is primary radiation therapy, consisting of external beam radiation using megavoltage radiation energies and brachytherapy. Low-dose-rate brachytherapy (LDR) significantly reduces the rate of local recurrence. The use of high-dose-rate brachytherapy (HDR) has been increasing, although more studies are needed to define optimal fractionation schemes as well as long-term complications of this method.

Cytotoxic chemotherapy for advanced cervical cancer is currently under study. Cisplatin is the drug with the best documented activity of any single agent. At present there is no evidence that the addition of other drugs improves survival. Patients with locally recurrent disease are treated with the modality not previously received. Patients who have had a hysterectomy should receive pelvic radiation therapy. Patients who have had maximal radiation therapy may have surgery, depending on the site of recurrence and extent of disease. The clearest role for surgical therapy is for centrally recurrent disease. For most patients, tailored pelvic exenteration remains the standard surgical approach. Aggressive therapies for recurrent disease after radiation are emotionally, physically, and economically costly, and this should be considered in making treatment decisions. Palliative treatment is appropriate for patients with symptomatic disease and can be achieved in most patients by radiation therapy. Oncologists should assure patients that psychological support and adequate treatment of 
all symptoms, including pain, are part of the treatment plan.

\section{What are new directions for research in cervical cancer?}

In the area of prevention, more research is needed on the modification of high-risk behavior in young people. In addition, research is needed on the optimal methods of evaluating and treating HIV-positive women with cervical lesions; improved screening in populations that are typically underscreened; provider behaviors that influence patient and clinician compliance with Pap smear screening; and methods of improving the accuracy and interpretation of cytologic sampling techniques, including liquid-based systems and computer automation. Also needed is research to develop markers to predict which women with low-grade lesions are likely to develop high-grade lesions or cancer. Support should also be given to research on topical microbicides that may prevent HPV infection.

Additional research is needed to improve staging, treatment, and quality of life for cervical cancer patients. Included among these research needs are investigations into optimal pre- and posttreatment imaging, prognostic markers to improve treatment selection, laparoscopic surgical techniques, radiobiology, and the addition of systemic chemotherapy to radiation therapy.
Cervical cancer can, in theory, be prevented and treated by HPV vaccine therapy; this research holds promise for having a profound impact on this disease.

\section{SINOPSIS}

\section{El cáncer de cuello uterino: resumen de la declaración de consenso de los NIH}

Con el propósito de examinar algunos aspectos aún no definidos del tratamiento del cáncer de cuello uterino y de la calidad de la vida de los pacientes, el Instituto Nacional del Cáncer (EUA) y la Oficina de Aplicaciones Médicas de la Investigación, pertenecientes a los Institutos Nacionales de Salud (NIH), convocaron una Conferencia para el Desarrollo de Consenso sobre el Cáncer de Cuello de Útero. El panel de expertos, que se compuso de 13 miembros, se concentró en los siguientes interrogantes: 1) ¿Cómo se pueden fortalecer las iniciativas para prevenir el cáncer cervicouterino? 2) ¿Cuál es el tratamiento apropiado del cáncer de cuello de útero en estadio temprano? 3) ¿Cuál es el tratamiento adecuado del cáncer cervicouterino recurrente o en estadio avanzado? 4) ¿Qué nuevos rumbos seguirán las investigaciones sobre el cáncer de cuello de útero? En este informe se resumen las conclusiones a las que se llegó en la Conferencia sobre estas cuestiones. La declaración de consenso se puede pedir gratuitamente a los NIH. 